\title{
Identidade cosmopolita global na prática educativa: da utopia à realidade
}

\author{
Pricila Kohls dos Santos ${ }^{1}$ \\ Pontifícia Universidade Católica do Rio Grande do Sul, Professora Colaboradora
}

Gárcia-Rincón, Cesar de Castro. Identidad Cosmopolita Global: Un nuevo paradigma educativo-social para un mundo nuevo. Madrid: PPC Editorial, 2016. 284 p.

Vivemos tempos de economia e sociedade globais. As distâncias físicas foram encurtadas, em certa medida, pelo advento da tecnologia de informação e comunicação. O público e o privado passam por novas configurações, e cada vez mais necessitamos compreender que a humanidade é uma só vivendo em culturas distintas, porém complementares entre si.

Nesta direção, o livro Identidad Cosmopolita Global: Un nuevo paradgima educativo-social para un mundo nuevo organizado por César Gárcia-Rincón de Castro, a partir de um projeto desenvolvido para os educadores da Compañía de María, entidade filantrópica que tem projetos educativos em diferentes países do mundo, apresenta uma reflexão inicial sobre as consequências da globalização para as relações de ensino e de aprendizagem e, ainda mais, para a necessidade de aprendermos a olhar para as individualidades e a globalidade para vivermos uma cidadania compartilhada e cosmopolita.

Nesse sentido, os escritos deste livro são impulsionados pelo seguinte questionamento: “¿Podremos vivir juntos?”. Ou seja, partem do princípio de que o tema gerador para a reflexão e explanação, ao longo da leitura, esteja voltado à real possibilidade de vivermos juntos. Nesse sentido, apoiam-se nos preceitos preconizados pela filosofia da Compañia de Maria para repensar uma prática educativa a partir do desenvolvimento de um projeto humanizador e ao mesmo tempo global.

Assim, partem da proposta pedagógica desenvolvida nos centros educativos da Compañia de Maria em todo o mundo, sendo esta baseada na estratégia de desenvolvimento de competências educativas elaborada por uma equipe de especialistas que são os autores participantes desta obra. De tal modo, o

Doutora e Mestre em Educação pela Pontifícia Universidade Católica do Rio Grande do Sul. 
autor procura situar o leitor no panorama histórico em relação ao desenvolvimento humano e aprendizagem, apontando possibilidades para o fazer global a partir do local (aqui entendido como contexto local), ou seja, a partir das individualidades para, assim, apresentar o papel do novo docente que leva em consideração a diversidade, a solidariedade, o humanismo, a identidade e a reflexividade para o desenvolvimento de competências para o desenvolvimento e a prática da identidade cosmopolita global.

O livro é dividido em seis capítulos, mais o epílogo, os quais abarcam os grandes temas citados anteriormente, bem como possibilidades práticas para o desenvolvimento de competências e alternativas para sua avaliação ao longo do processo. Tais capítulos contam com o auxílio dos especialistas, mencionados anteriormente, nos temas de maior especificidade. No primeiro, intitulado A Identidade Cosmopolita Global como novo paradigma educativo e social no século XXI e na Compañia de Maria, o autor conta com o auxílio do especialista Luis Aranguren Gonzalo, que procura definir e situar o leitor na reflexão sobre a Identidade Global Cosmopolita no atual contexto sociocultural e global em que vivemos. Ainda assim, apresenta uma reflexão acerca da pirâmide de níveis neurológicos como proposta pedagógica para o modelo social de identidade, e ao final do capítulo apresenta as quatro dimensões-chaves para as competências necessárias para o desenvolvimento da identidade cosmopolita global.

Ainda nesse capítulo são destacados os quatro pontos-chaves para a identidade cosmopolita global, os quais graficamente estão representados por peças de quebra-cabeças como elementos que se encaixam, para a construção de algo maior e com sentido, representando uma sociedade inclusiva na qual todas as peças são necessárias e complementares. As quatro chaves da identidade cosmopolita global são: Diversidade e Inclusão - que todos têm espaço e direitos adquiridos e respeitados, desde a perspectiva cultural, econômica e os modos de aprendizagem, sendo disponibilizados a todos os mesmos direitos e oportunidades; Solidariedade e Justiça - sendo a solidariedade, as ações, os projetos e a justiça o viés orientador para cada uma das ações; Utopia e Historicidade - partem da utopia de um outro mundo possível e com a união de homens e mulheres novos, que desenvolvem ao máximo suas competências a serviço de todos, tendo a história e o passado como chave para se pensar o futuro; e, ainda, pensar nessa utopia a partir das experiências, positivas e negativas, com o intuito de mudar a realidade atual, pois não se pode pensar o futuro deixando de lado a linha do tempo histórica da humanidade. Afinal, o futuro 
se constrói a partir dos elementos do passado, com as experiências vivenciadas no presente; Identidade e Reflexividade - na qual a identidade individual e coletiva é construída por processos reflexivos e discursivos em que estão em jogo os valores e os direitos humanos perpassados pelos critérios éticos de discernimento e tomada de decisões. Assim, objetiva uma identidade global cosmopolita em detrimento de uma sociedade etiquetada, passiva ou desconectada do mundo.

No segundo capítulo, A educação para o desenvolvimento humano: um olhar histórico para compreender onde estamos e para onde queremos ir, a autora Ma Cecilia Múnera López apresenta a definição para o conceito de desenvolvimento humano sob o ponto de vista da interdisciplinaridade e como esse conceito pode superar a visão tradicional das abordagens dependentes, econômicas, eurocêntricas ou colonialistas, levando em consideração que o conceito de desenvolvimento humano necessita ser abordado desde os enfoques social, humano e econômico como dependentes e complementares. Nesse capítulo também são abordados o papel da igreja na justiça e solidariedade, bem como o enfoque da aprendizagem global no contexto do século XXI, a chamada Educação para o Desenvolvimento Global (EDG). Contamos com o auxílio do autor Miguel Ardanaz, que nos convida a ver a EDG a partir de uma nova perspectiva, superando a abordagem tradicional e procurando mais dos processos de ensino e aprendizagem global, pois na EDG são apontados quatro níveis de aprendizagem: 1. com diversidade global; 2. com enfoque de direitos; 3. com diálogo e participação; e 4. com pensamento crítico e criativo. Esses quatro níveis têm como pano de fundo o ciclo orientado pelo movimento da sociedade que coopera e da que aprende. A Sociedade que coopera é uma sociedade inclusiva, e, por conseguinte, uma sociedade que aprende, no qual a diversidade é incorporada ao processo de aprendizagem, na qual se aprende a partir da experimentação e da reflexão pessoal, para toda a vida e todas as pessoas e contextos.

No capítulo $A$ identidade cosmopolita global e sua concretização progressiva em situações de aprendem experiencial e por competências, o autor apresenta um modelo de competências baseado na contextualização progressiva do saber, saber fazer e saber ser para a identidade cosmopolita global, bem como o novo papel do docente nesse contexto de aprendizagem por competências, no qual o professor é o projetista do conteúdo e o diretor das situações de aprendizagem, atuando como animador e estimulador de novas aprendizagens. 
O autor afirma que todas essas competências são programadas e divulgadas em uma série de repertórios ou tabelas de competência em várias situações de aprendizagem que são elaboradas pelos professores e que resultam na ideia de desempenho. O desempenho implica o desenvolvimento de três dimensões-chaves: o saber enquanto conhecimento, o saber fazer, que são as capacidades, e o saber ser, que se refere às atitudes.

No quarto capítulo, intitulado $O$ desenho de situações de aprendizagem de identidade cosmopolita global: metodologias de desenvolvimento de competências, aborda que para educar por competências é preciso uma mudança paradigmática do educador, passando de uma pedagogia instrucional, na qual o estudante é apenas o espectador, para uma pedagogia construtiva, na qual o estudante é ator/autor de conhecimento. Para tal, retoma o ciclo de aprendizagem experiencial de David Kolb, também conhecido como Ciclo de Kolb, o qual é baseado em quatro passos de sequência lógica e processual (experienciar, refletir, conceituar e aplicar) que, na experiência do autor, é uma ótima ferramenta para o desenvolvimento de competências. Nesse capítulo o autor também apresenta alguns modelos para o planejamento de situações pedagógicas para colocar em prática os conceitos e preceitos apresentados nos capítulos anteriores, utilizando o Ciclo de Kolb como orientador para o planejamento educativo.

No capítulo quinto, A avaliação da competência identidade cosmopolita global, o autor conta com a participação de Isabel Muñoz e Belén Urosa, como especialistas em avaliação de competências, as quais fornecem ferramentas para avaliar o aprendizado, explorando, a partir de exemplos práticos, como tais ferramentas podem ser utilizadas para avaliação de competências. As autoras descrevem cinco passos para esta avaliação: 1. Definir a competência; 2. Identificar suas dimensões; 3. Estabelecer indicadores; 4. Estabelecer níveis de domínio; e 5. Dar forma ao instrumento de avaliação. Apresentam modelos de instrumentos de avaliação e salientam a importância da elaboração destes, atentando para a diversidade de situações/atividades avaliativas para que seja possível perceber o desenvolvimento das competências em diferentes situações.

No sexto capítulo, Forças centrífugas e expansivas da identidade cosmopolita global nas comunidades educativas, são apresentados aspectos intervenientes que podem não estar diretamente relacionados com o contexto de sala de aula, como é o exemplo da família, que aparece como parte do tríplice Família-Escola-Compañia de Maria; apontando que a educação em valores ocorre nesses três níveis de socialização. 
$\mathrm{Na}$ família, que é onde se encontra a base dos valores e, por isso, faz-se necessário trazê-la para perto, para o contexto educativo da escola. Na escola, que é o lugar onde se passa grande parte da vida e onde se situa a chave da plataforma educativa. E nas organizações sem fins lucrativos, como o caso da Compañia de Maria, as quais primam pelo desenvolvimento de uma sociedade mais justa e solidária, comprometidas com a experiência vivida dentro das instituições e que refletem na vida em sociedade.

Tomando como ponto central a figura do educador como dinamizador e catalizador da EDG, o autor compartilha algumas experiências de voluntariado escolar e juvenil, bem como o programa Young People on the Global Stage que busca, por meio de alianças internacionais, ferramentas de transformação social, ambas experiencias realizadas em escolas espanholas. Apresenta, também, uma ação social na Colômbia e a Rede Cántabra e a Rede Navarra de escolas solidárias, ambas como expressão direta do desenvolvimento da Identidade Cosmopolita Global, nas quais todos contribuem com experiências e inovações que podem inspirar todos nós que estamos comprometidos em fazer um mundo mais justo, humano e habitável.

Ao final, o autor apresenta, no epílogo, reflexões, ações e futuras investigações para não deixar apagar a chama daquilo que foi iniciado na direção da Educação para o Desenvolvimento Global, pois salienta que é urgente educar para um pensamento crítico e global, levando em consideração as virtudes criadoras que são inerentes do ser humano e que não podem deixar de ser estimuladas em prol de um crescimento em solidariedade para todos e com todos.

Nessa direção, a obra aqui apresentada representa uma importante fonte de consulta para subsidiar uma prática educativa mais contextualizada, mais humana e solidária, sem deixar de perceber as individualidades, tanto pessoais quanto locais, dos envolvidos com a educação e considerando as competências necessárias para a atuação em um mundo cada vez mais globalizado. Ainda, reflete a preocupação com o sentido maior da educação e com a possibilidade de esta ser uma importante fonte de transformação pessoal e social, levando em consideração o contexto global para a mudança da realidade local. Transformando a Identidade Cosmopolita Global de utopia em uma realidade possível, desde que, com a participação e envolvimento de toda a sociedade, começando pelas instituições de educação. 
